\title{
Evaluation of Content Management Systems Performance
}

\author{
Maitanmi Olusola ${ }^{1}$ and Idowu Sunday ${ }^{2}$ \\ ${ }^{1}$ Department of Computer Science, Babcock University, Ilisan Remo, Ogun State, Nigeria \\ ${ }^{2}$ Department of Computer Science, Babcock University, Ilisan Remo, Ogun State, Nigeria
}

\begin{abstract}
There are many web-authoring software like FrontPage and Dreamweaver, which are being used to develop and maintain websites. These web-authoring software are becoming inadequate because websites are becoming more dynamic with different contents types.

Content Management Systems (CMS) evolved as an alternative to such web-authoring tools because it escapes the burden of coding and enhances easy update of content. CMSs are both proprietary and open source, but due to cost, open source CMSs are preferred. Though, there are a huge number of open sources CMS available in public domain, it may be difficult to decide which of these would best suit a particular situation and yield best return on investment $(R O I)$.

Thus, this research work is aimed at evaluating some common CMSs in order to determine their usability. The problems that were addressed include selecting the right CMS based on some defined parameters, assessing ROI of the CMSs with respect to the needs of the content providers.

Literature and industry research review of CMS was examined; extensive literature was carried out on the existing work on the subject matter to consider some CMS which were chosen based on popularity. A web-based survey was conducted using an online questionnaire. The responses were quantitatively analyzed using some statistical techniques.

Considering a number of constraints in websites developments using CMS, report shows that joomla has the highest frequency of users, contents determine the choice of CMS while all CMS's ROI can be measured either tangible or intangible.
\end{abstract}

Keywords: Content Management System, Comparison of CMS, Open Source Software, Return on investment (ROI).

\section{Introduction}

As the World Wide Web (www) has matured, so have people's expectations of their Web experiences[1]. After becoming familiar with what they find and how to find it, web visitors have begun to expect more and timelier information from the Web sites they visit. Web managers, in turn, have had to find new ways of meeting these expectations. Content Management System (CMS) is not only on Web development, although that is where it is mostly practiced today. CMS is about gaining control over the creation and distribution of information and functionality[2]. It is about knowing what value you have to offer, who wants what parts of that value, and how they want you to deliver it. A CMS is software that enables non-information technology (IT) users to change web site content directly without help from IT department or web master. With a CMS, these non-technical users can create, edit, and publish content via a browser-based interface. The research work aimed at the evaluation of content management systems, its cost, technical and other associated benefitsto both developers and clients[2].

A research carried out by [3]suggested that CMS is as old as when people started creating Web sites. They did so by typing hypertext mark-up language (HTML) into plain text editors (such as Microsoft Notepad and notepad ++ ). As time moved on, the need for better tools grew, fuelled by enterprising product companies, less technically adept users, more ambitious Web sites, and the need to automate tedious tasks. At first, these new HTML authoring tools did little more than help users remember the secret syntax of HTML. Later, they began to be true WYSIWYG (what you see is what you get) environments for creating Web pages. Today, some of these tools add just enough management to serve as a nominal Web CMS for organizations with small sites and no additional publications. In the last few years, however, several commercial applications have beenreleased that perform content management in one way or another.

\subsection{Static and Dynamic Content}

A research carried out by [4] gave a comprehensive meaning to static and dynamic web pages as follows:A static Website is a set of HTML pages and related file resources (such as images), all of whichare stored as individual files on a Web server. Static pages are pre-builtby definition; they are not created on the fly or personalized in any way, beyond the logic contained within the scriptfor each static page. 


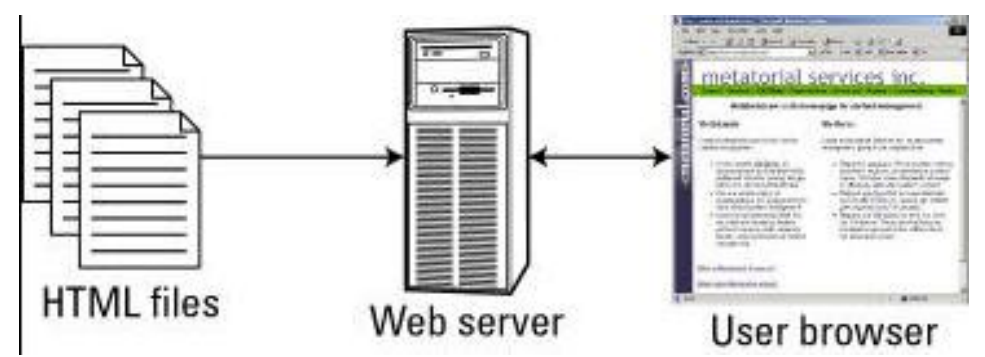

Fig.1. A static content

A limitation of a static Web content is lack of flexibility and scalabilitybeyond a few hundredpages, managing a static Web content can be tedious because content must be updated oneach and every page [4].

A dynamic Website, sometimes known as a database-driven site, is a system for producingWeb pages on the fly as users request them.A data source (a relational database, or possibly an extended mark-up language (XML) structure) on the Web server receivesa query in response to a user clicking a link[5].

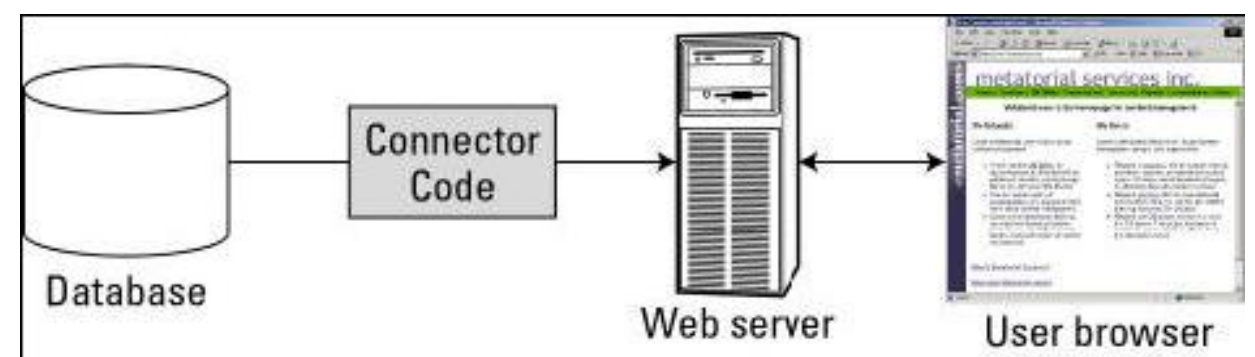

Fig. 2 A dynamic content

Some of the identified problems are:

To show how CMS users can calculate returns on investment (ROI) without disclosing official information, to demonstrate the factors of CMS that can improve usability for better users' experience, and to determine the factors why CMS is used for a particular audience.From the foregoing problems, the objectives of this research work therefore is to: evaluate the content management systems performance in terms of usability, resilience to attack; response to internet connection, and utility; investigate the various returns on investment of both the contents providers and developers; compare the CMS-based websites vis-à-vis usability, accessibility and user friendliness; analyse various criteria for choosing a CMS and provide appropriaterecommendations for selecting a CMS. To achieve these objectives this study isdivided into five sections. Following this introduction, SectionII, examines existing literature on CMS, Section III,presents the methodology employed in collecting and analysing data, Section IV, presents an analysis of the collected data; andSection V, deals with the conclusion and recommendations drawnup from the study.

\subsection{Content Management System}

\section{Review Of Literature}

According to CMS buyers' guide cited by [6]that content management provides many advantages over traditional methods of information editing. Many of the benefits are derived when distributed teams of people are responsible for coordinating and contributing to different content repositories which are listed below:

\subsubsection{Content Empowerment}

Content empowerment according to [7]is a Content management (CM) solution that can help companies increase the number of repeat visitors and ultimately increase revenues, by offering timelier and more valuable content. Content Management solutions offer Web authoring, editing, and publishing capabilities. Empowering content involves making better use of information and putting control in the hands of content owners. These are further classified as follows:

2.1.1.1 Content Ownership:empowers business users to quickly and efficiently update their online information without technical intervention. Having full content ownership expands the opportunities for subject matter experts to make their information available to their specific audiences.

2.1.1.2 Content Accessibility: Content accessibility is powered by the CMS, which repurposes content into multiple formats, and helps ensure that disability compliance is met. Content repurposing takes a single source 
of information and applies the necessary changes to automatically generate various outputs including standard HTML, printer friendly HTML, handheld Wireless Markup Language (WML), Portable document format (PDF), and XML. In addition, the content is checked for compliance to make sure certain conditions are met for persons with disabilities such as blindness or epilepsy [8].

\subsection{CMS Costs and Revenue}

According to [9]CMS significantly lowers costs associated with managing information online. Manual technical steps in the process are eliminated and the webmaster bottleneck is eradicated.

Apart from the reduction in cost of creation and maintenance explained above, another researcher [6] mentioned that a CMS provides new ways to increase revenues. With lower time-to-market for content and the empowerment of business users, new opportunities are available on which to capitalize.

2.2.1 Time Sensitive Opportunities: New opportunities arise when information is published online in a matter of minutes as compared to hours or days [8]. A good example exists in media publishing. Breaking a news story ahead of the competition brings a first mover advantage, drawing additional visits to the site and increased income from sponsors. A CMS improves the speed of online contents publishing.

2.2.2Fresh Content Encourages Return Customers: A research carried out by [16] revealed that as a customer, you would visit a site that is updated once a week rather than a site that is updated once a year. A frequently updated site should have a fresher content which will encourage customers to return, resulting in increased revenue opportunities.

\subsection{Accountability Improvement and Consistency Management}

The government of Alberta in Canada saw an improved accountability to CMS in a document [24]. It illustrated that accountability at both the content creation and users are important when managing information online. With effective accountability measures in place, management is free to focus on more pressing issues as discussed below:

2.3.1 Audit Trail:The audit trail, available at both the user and CMS creation level, provides a snapshot of the history of content changes. With detailed records available, a CMS institutes full accountability and helps motivate employees to complete work in a timely manner.

2.3.2 Version Control:Version control is the automatic backing up of content as changes are made. With version control in place, business users are given peace of mind that errant actions will not lose information. In addition, the versioning mechanism allows for full compliance with legal and government regulations.

A research by [28] mentioned that content published on a site is often displayed in an inconsistent manner, confusing the site visitor. Rather than force a visitor to relearn the navigation menus and layout several times for one site, a site should enforce display standards that maintain consistency throughout. In view of this, [28] further suggested by the following measures:

2.3.3 Presentation Consistency: Content should be presented within pre-defined templates whenever possible. Templates provide a mechanism for maintaining a consistent look and feel, thereby creating a professional image of uniformity for the site visitor[20].

2.3.4 Brand Integrity:Brand integrity is enforced with a CMS by limiting available logos and layout design in a manner consistent with corporate policies. Too often a user, in a non-malicious manner, publishes graphics and content outside the corporate brand policies[25].

\subsection{Benefits of Content Management System}

Website can be created using the Content Management Systems (CMS) or created from start using the HTML codes or other traditional methods. While the maintainability of CMS could be done automatically or through traditional non-CMS methods as discussed below by [3].

Any organization or institution that interacts a lot with the public and is concerned about good image making and also publish a lot of content from a number of authors should seriously consider a CMS, [18]. A quality CMS has many benefits in an institution publishing process. Some of these benefits are listed below:

i. A good CMS makes it easier for people to create, edit and publish content on a website, it allows nontechnical authors and editors to easily and quickly publish their content [27].

ii. A good CMS makes it easier for an institution to manage who creates, edits and publish contents. 
iii. By easing technical hurdles on the publication of content, a CMS can reduce the need for training, while facilitating more people to publish [27]. At the same time it reduces the daily stream of calls to the IT unit for changes to the website.

iv. A good CMS reduces time-to-publish, the faster you get key content publishedthe more value it creates [13].

v. A good CMS allows for the design of a common and consistent content architecture (metadata, classification, navigation, search, layout and design), [13]. It also allows for consistent management of metadata through content template structures.

vi. A better security of content is guaranteed by using a good CMS. It can control who is allowed to publish onto the website and who is allowed to see what content. Also, it can allow users to easily measure the success of your publishing efforts.

\section{Data And Methodology}

The research design used in this research work is the descriptive survey method; it involves the use of a representative sample from the population. The population of the study is the entire nation. A sample size of 100 using the convenient sampling procedure. Only Computer literates were included in the sample since they are the one that can respond independently to the questionnaire.

The method used to collect data for this study is online web survey using a structuredquestionnaire. A total of 100 copies of thequestionnaire were broadcasted online out of which 55 copies were returned. The responses from the respondents were collated and analysed using the simple percentage procedure.

\section{Analysis Of Data}

The responses to the questions in the questionnaire provided the basis for the following analysis. Table 1 , below show frequency and percentages of CMS and users experience.

Table 1. Frequency and percentages of CMS and users experience

\begin{tabular}{|l|r|r|}
\hline CMS Types & Frequency & \% Frequency \\
\hline Joomla & 25 & 45.45 \\
\hline Drupal & 8 & 14.55 \\
\hline WordPress & 7 & 12.73 \\
\hline Typo3 & 12 & 21.82 \\
\hline Other(s) & 3 & 5.45 \\
\hline Total & $\mathbf{5 5}$ & $\mathbf{1 0 0}$ \\
\hline
\end{tabular}

Source: Field Survey

Table 1 shows clearly that Joomla has the highest frequency of users. 25 out of 55 respondents agreed that they use Joomla at a percentage of $45.45 \%$ as shown in figure. 3 while the least came from other types of CMS which is 3 with a percentage of $5.45 \%$. The reason for this high rate of use of Joomla may not be unconnected with the nature of the sample selected. The study used only Computer literate people who by all possibilities are expected to have fair knowledge of CMS and it types.

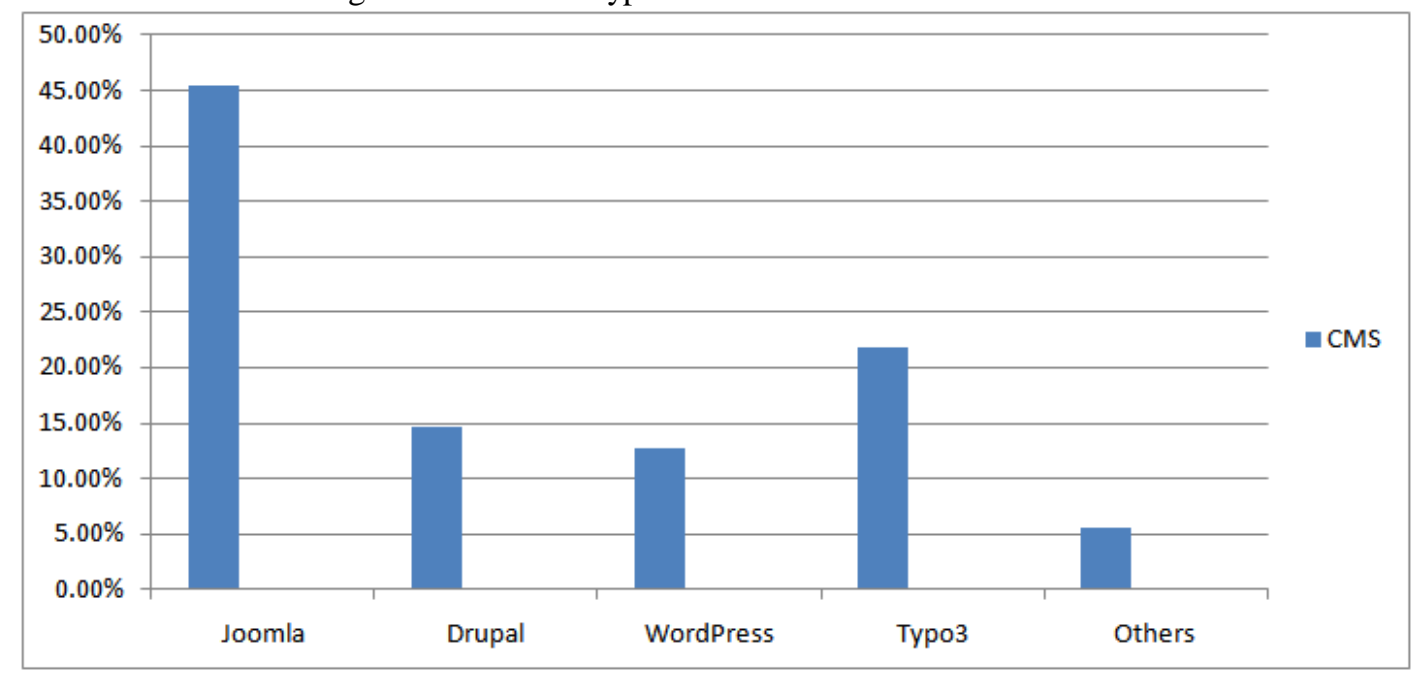

Fig. 3 Showing the Percentage of CMS and Users' experience 
Table 2Frequency of respondents rating CMS usability Source: Field survey

\begin{tabular}{|l|r|r|}
\hline Non Technical rate & Frequency & \% Frequency \\
\hline Very Good & 18 & 32.73 \\
\hline Good & 35 & 63.64 \\
\hline Not very good & 0 & 0.00 \\
\hline Poor & 0 & 0.00 \\
\hline N/A & 2 & 3.64 \\
\hline Total & $\mathbf{5 5}$ & $\mathbf{1 0 0}$ \\
\hline
\end{tabular}

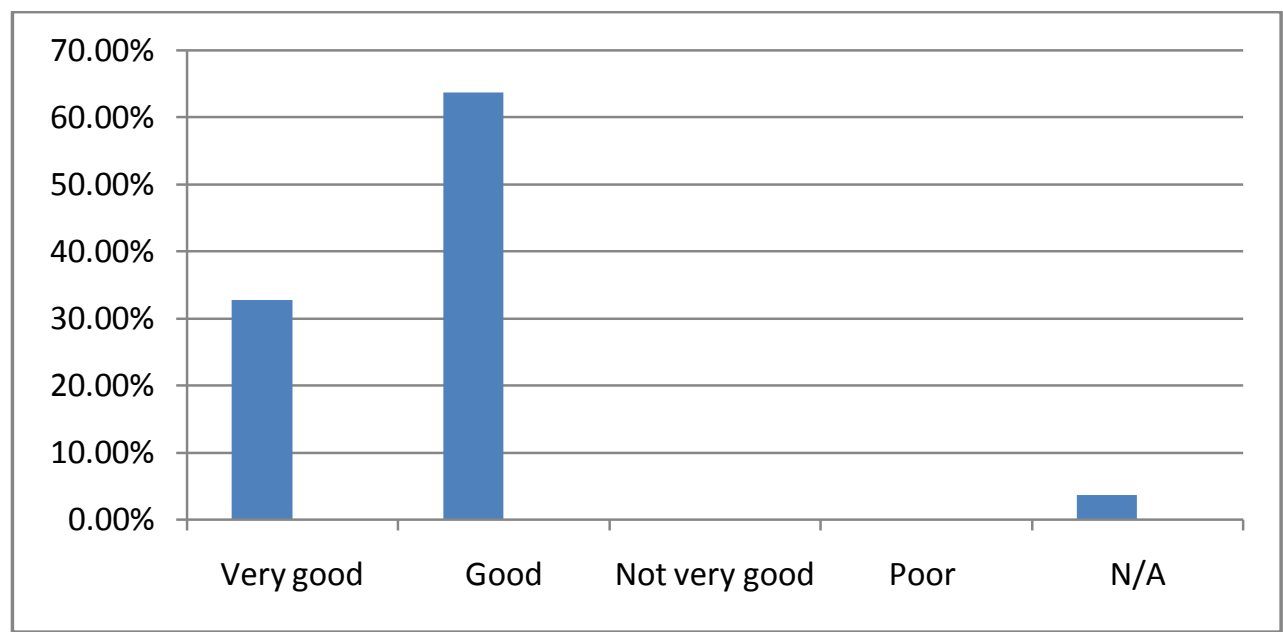

Fig. 4 showing the percentage usability rate of CMS

Table 2and figure4 shows the usability rate of CMS amongst non-professional users. The results show clearly that 18respondentsperceived that CMS was very good in terms of its usability, and user friendliness, and auto assistance while 35 respondents said it was good.

The Computer skills and knowledge of users may necessary not be a barrier to its use. This is possible because CMS are as simple as Microsoft Office suits which require your little typing skill to setup and configure your platforms. Therefore, $63.64 \%$ respondents believed that it was good.

\subsection{The Returns on Investment}

Returns on Investment (ROI) of websites is not just returns on financial investment; it encompasses total success of the investment by comparing what the website is doing with the expected goals set when it was started. If answers to the following questions are yes, then there are improvements in one ROI:(i) Are you getting the targeted traffic you set out to get?,(ii) Are you getting the feedback from users on areas that need improvement?,(iii) Is the increase in website converting to increases in sales?ROI is the difference between how muchthe usersinvestson the investment and how much is gained on the investment including the user's satisfaction [27].

\subsubsection{Direct Financial ROI}

If the monetary return of online marketing activities must be calculated, the financial definition of ROI should be clear. In general, it can be stated that the business definition of return on investment refers to the measurement of revenue or profit that a company generates from a specific investment or several investments[27]. In other words, it measures how efficiently the firm uses its capital to generate profit.

The most basic ROI formula resulting from the above definition is:

$\mathrm{ROI}=\underline{\text { revenues-investment }}$

: equation

Investment 
Table 3Opinion onReturns on Investment Source: Field survey

\begin{tabular}{|l|r|r|}
\hline ROI of sales & Frequency & \% Frequency \\
\hline Very Good & 18 & 32.73 \\
\hline Good & 32 & 58.18 \\
\hline Not very good & 4 & 7.27 \\
\hline Poor & 0 & 0.00 \\
\hline N/A & 1 & 1.82 \\
\hline Total & $\mathbf{5 5}$ & $\mathbf{1 0 0}$ \\
\hline
\end{tabular}

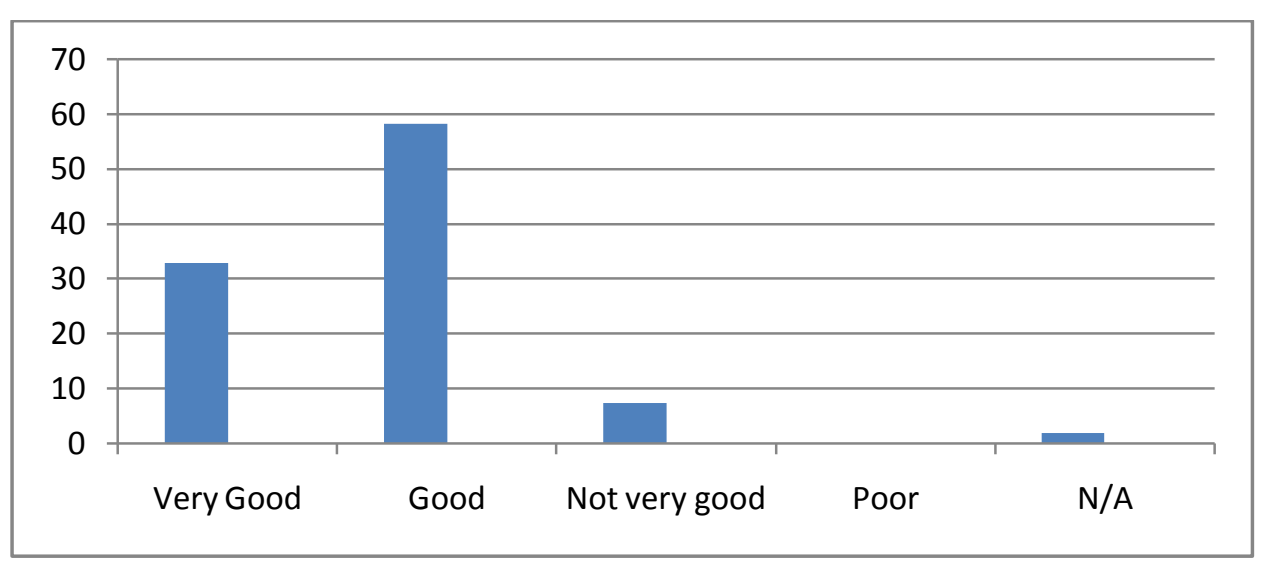

Fig. 5showing the percentage returns on investment

Results according to Table 3 Shows that 18 respondents agreed that IT investmentsyieldedgood revenue while 32 respondents admitted revenue generation from IT investments was good. Figure5shows that the highest bar chart went to the respondents who agreed that the ROI was good with $58.18 \%$.

\subsection{Table 4 Features of some Selected CMS}

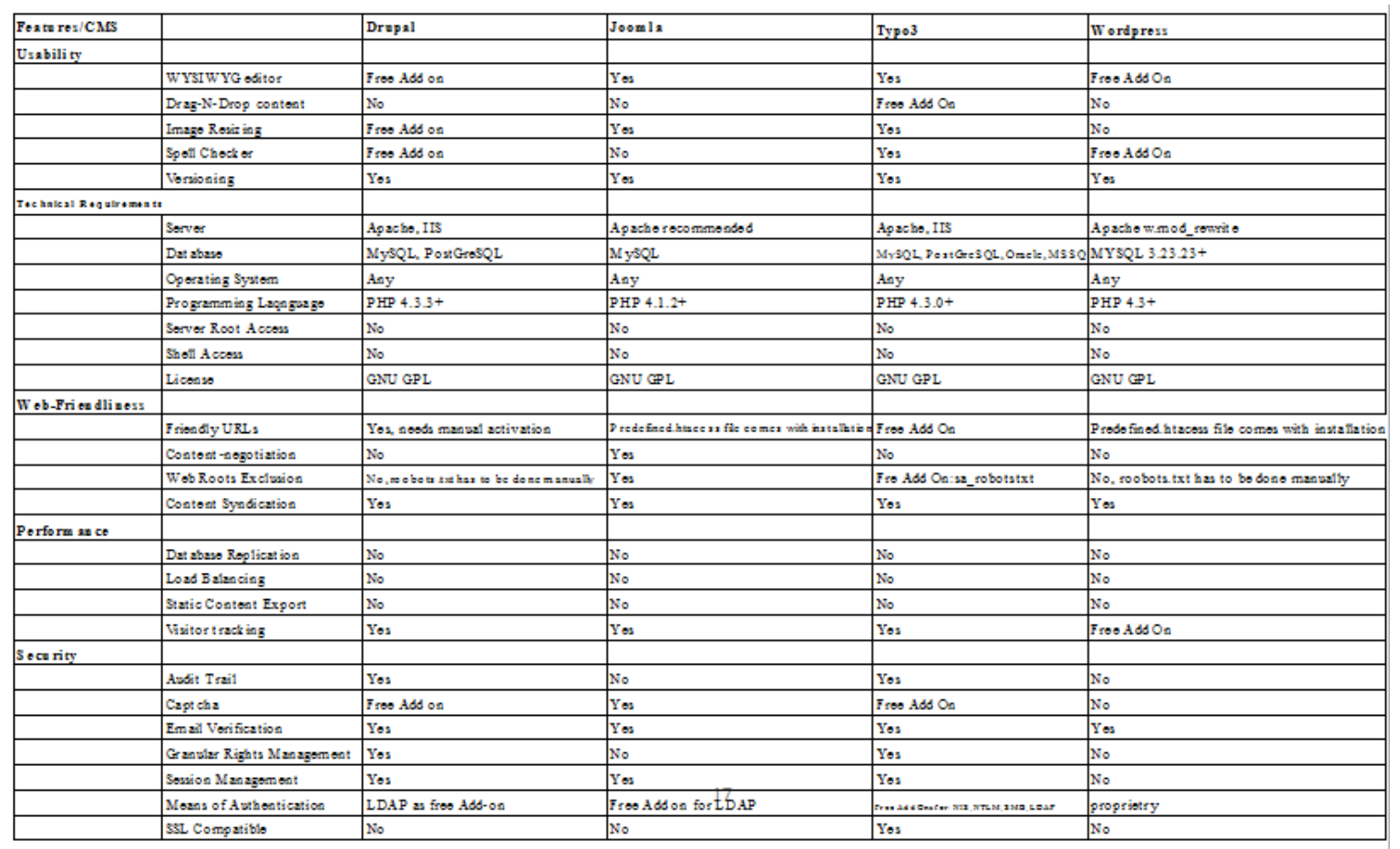


Table 5 Features of some Selected CMS Continued

\begin{tabular}{|c|c|c|c|c|c|}
\hline Features/CMS & & Drupal & Joomla & Typo3 & Wor dpress \\
\hline \multicolumn{6}{|l|}{ Se curiity } \\
\hline & Problem Notification & No & No & Yes & Yes, but limited \\
\hline & Sandbox & No & No & Yes & Yes \\
\hline \multicolumn{6}{|c|}{ Built-in applications } \\
\hline & Search Engine & Yes & Yes & Free add-on & Yes \\
\hline & Gvest Book & Free add-on & Free add-on & Free add-on & No \\
\hline & Graphs and Charts & No & Free add-on & Free add-on & No \\
\hline & Photo Gatlery & Free add-on & Free add-on & Free add-on & Free Add-on \\
\hline & User Contributions & Yes & Yes & Yes & Yes \\
\hline & Syndicated Content & Yes & Yes & Yes & Yes \\
\hline \multicolumn{6}{|l|}{ Support } \\
\hline & Development Community & Yes & Yes & Yes & Yes \\
\hline & Public Forum & Yes & Yes & Yes & Yes \\
\hline & Public M ailing List & Yes & No & Yes & Yes \\
\hline & Profes sional Hosting & Yes & Yes & Yes & Yes \\
\hline & Users Conference & No & Yes & Yes & No \\
\hline & Certification Program & Yes & No & No & No \\
\hline & Commercial Manuals & Yes & Yes & Yes & No \\
\hline & Commercial Support & Yes & Yes & Yes & No \\
\hline & Commecial Training & Yes & Yes & Yes & No \\
\hline
\end{tabular}

\section{Conclusion And Recommendation}

From the analysis above, it appearsthat credibility of a website is most often not valued by the freshness of the content. A frequently updated content goes a long way in not only retaining old customers but also play a big role in gaining new customers.

Fresh and updated content not only ensures a dedicated fan base for a site, it also does the site a world of good when it comes to the Search Engine Optimization of a venture, ensuring that the site is most valued by the most coveted Search Engines which in turn increases the users ROI.

It also appears that an efficient CMS ROI is not only tangible but can also be an intangible benefit based on satisfaction received. Despite the fact that Table 1 shows that Joomla has the highest frequency of users, the researcher would have like to test for the global awareness of CMS which time didn't permit. The researcher therefore proposed this for further consideration.

\subsection{Recommendations}

In addition to the above and based on the analysis, the researcher would also recommends to all new and prospective users of CMS that there are quite a lots more valuable information such as volume of contents, types of network, frequency of update among other that would have to be considered before settling down for a particular CMS. The research was not meant to promote one CMS type over another but to point attention to various support features which they possess.If users' needs are not very complex, if a user is planning to hire someone to build a site that is less than several hundred pages, and hierarchically arranged, any of the available CMS will work fine. But if a developer is trying to build a site for the banking sector or any financial institution where there is a need for strong security and reliability, then the developer can compare these CMS security wisely and settle down for the one which is less prone to attack.

\section{Conclusion}

Choosing a CMS can be a long and difficult process, especially since there are a large number of content management systems available. Sourceforge.net alone lists around 600 active open source CMS projects one can choose from. The selection of a content management system depends on a variety of criteria such as content, structure, complexity of work among others.

\section{References}

[1] Gay, L. \& Robinson, J.(2001).Content management: The Quest, Presentation at the CUMREC Annual Conference, http://www.educate.edu/ir/library/pdf/CMROI32.pdf retrieved on 20/10/2010

[2] Bachmann, D., John, E., \& Gary, V. (1996). Tracking the Progress of E-Mail vs. Snail-Mail, Marketing Research: A Magazine of Management \& Applications, 8(2), 30-35.

[3] Boiko, B. (2002). "Introducing the Major Parts of a CMS": A CM Domain White Paper.http://206.253.219.101/biblev1/Whitepapers/Boiko Whitepaper WPMISC1.pdf retrieved on 27/12/2010

[4] B. BoikoContent Management Bible, Second Edition, Wiley Publishing Incorporation Canada, 2005

[5] Byrne, T. (2005a). Oh What A Feature: Functional usability of web content management systems. EContent, 28(5).

[6] Business link, (2008). 'Calculation of ROI'http://www.elcnetwork.ca/ebusiness/pwt_return_on_investment.pdf retrieved on $12 / 10 / 2010$

[7] Suchitra P. ( 2002). 'Effective Web Content Management: Empowering the Business' User Workshop on Information Resource Management 13th-15th March 2002 
[8] Philipp, R., (2006). 'Evaluation of content management systems', A University BachelorThesis, University of Innsbruck Innsbruck, AustriaMike C., Amie W., \& Ian C. (1999). 'The Intranet Opportunity, the benefits of a content Management System'. Making money with googleAnderson, S. E. \& Bruce M. G. (1995). "Using Electronic Mail Surveys and ComputerMonitoredData for Studying Computer-Mediated Communication Systems," Social Science Computer Review, 13(Spring), 33-46.

[9] J. O BrionyResearching Information Systems and Computing, Sage, PublicationsLtd. London. 2009

[10] Brian, S., Rodger, G.\& Tim, T.(2008).Center for applied research, Research bulletin, volume2008, issue 22, October 22, 2008 Content management system for enterprise http://net.educause.edu/ir/library/pdf/ERB0822.pdf retrieved on 29/12/2010

[11] Brian P., (1999). ‘Content Management': The Collaborative E-Business,www.entmag.com/displayarticle retrieved on 30/11/2005.

[12] Byrne, T. (2005b). Oh What A Feeling: Applying usability principles to your CMS. EContent,28(3).

[13] Comley, P. (1996). 'The Use of the Internet as a Data Collection Method,'http://www.sga.co.uk/esomar.html retrieved on 1/3/2011

[14] Corstjens, M. \&Merrihue, J. (2003): ‘Optimal Marketing', Harvard Business Review vol.81, issue 10 pp.114

[15] CUE (2003). 'Learning Management Systems for the rest of us'. Corporate University

[16] Enterprise.http://www.uv.es/ticape/pdf/CUE-LMS\%20White\%20Paper.pdf retrieved on 20/12/2010Drupal http://drupal.org/ retrieved on $13 / 1 / 2011$

[17] Frøkjær, E., Hertzum, M., \&Hornbæk, K. (2000). 'Measuring Usability' Are Effectiveness,Efficiency and Satisfaction Really Correlated? Chi '00

[18] Gilbane. (2003). Report http://gilbane.com/artpdf/GR11.2.pdf retrieved on 2/7/2011

[19] S. A. Idowu $22^{\mathrm{ND}}$ National Conference and $30^{\text {th }}$ Anniversary Conference Proceedings volume 19 of Nigeria Computer Society, Theme'Enabling Cappacity of Information Technology for sustainability National Development' (ENCITDEV) pp. 77.2008

[20] Joomla http://www.joomla.org/ retrieved on 13/1/2011

[21] Kristin, C. (2000).'The Drupal Content Management System’: Choice and implementationplans for aUCARwide web Content Management System

[22] O'Really, T. (2005). What is Web 2.0: Design patterns and business models for the nextgeneration.http://www.oreillynet.com/pub/a/oreilly/tim/news/2005/09/30/what-is-web-20.html, retrieved on 12/1/2011

[23] Princeton University ( 2008). Office of Communications, Version 2.2 'Guide to CreatingWebsiteInformation Architecture and Content'

[24] Rena, T. (2000). 'Content Publishing Strategies: Creating Usability While Building the System Architecture'http://www.welchmanpierpoint.com/sites/files/Content\%20Publishing\%20Strategies.pdfretrieved on 10/10/2010

[25] Robertson, J. (2007). Usability Principles For CMS Products.

[26] http://www.steptwo.com.au/papers/kmc_usabilitycms/pdf/KMC_UsabilityCMS.pdf.retrieved on 12/2/2011

[27] Thorp, J.(1999).The Information Paradox. Montreal: McGraw-Hill.

[28] Typo3 http://typo3.org/ (Developer Portal) retrieved on 13/01/2011

[29] Wordpresshttp://wordpress.org/ retrieved on 13/01/2011 